\title{
Effects of Corrosion and Ribs on Low Cycle Fatigue Behavior of Reinforcing Steel Bars S400
}

Ch. Alk. Apostolopoulos and V.P. Pasialis

\author{
(Submitted November 3, 2008; in revised form June 2, 2009)
}

\begin{abstract}
The results of an experimental study for assessing the degradation of the fatigue properties of reinforcing steel bars grade $\mathbf{S 4 0 0}$ caused by exposure to laboratory salt spray corrosion environment are presented. For this purpose, low cycle fatigue (LCF) tests were carried out. Furthermore, the effect of ribs on the fatigue strength was recorded. Results are indicative of the catalytic impact of corrosion on LCF behavior. Since two important degradation factors such as corrosion and LCF are functions of time, it appears that the reliability of steel $\mathbf{S 4 0 0}$ is also time dependant. Additionally, the presence of ribs on material's surface affects significantly the fatigue behavior by reducing energy dissipation and duration of test.
\end{abstract}

Keywords fatigue behavior, low cycle fatigue, ribs on material surface, salt spray corrosion, steel bars S400

\section{Introduction}

Steel reinforced concrete exists almost in every heavy construction including homes, stadiums, schools, bridges, and so on. Despite some obvious disadvantages of its use (increased own weight, bulk size), reinforced concrete (RC) offers really important advantages such as durability and low maintenance cost.

In Greece, from the early 1960s to late 1990s, S400 grade steel was used as reinforcement in RC structures according to Hellenic code ELOT 959 which is equivalent to BSt 420 grade steel according to DIN 488 standard. Despite its replacement since the late 1990s (mostly by BSt500s grade steel), S400 steel reinforcements still exist in most RC structures now in Greece. During the prolonged service time of these structures, damage has accumulated on their load-bearing elements, caused by corrosion and earthquake loading, resulting in decreased residual strength bearing capacity.

Corrosion and earthquake loading may dramatically affect the mechanical properties of reinforced concrete. Both concrete and steel should be expected to deteriorate in the course of time. Although concrete's deterioration is taken into consideration for repair and rehabilitation purposes, steel reinforcement's mechanical properties are mistakenly considered to be unaffected by corrosion and dynamic loading and therefore considered to remain constant with time (Ref 1$)$. However, a number of experimental researches have shown that effects

Ch. Alk. Apostolopoulos and V.P. Pasialis, Department of Mechanical Engineering and Aeronautics, University of Patras, Panepistimioupolis Rion, 26500 Patras, Greece. Contact e-mails: charrisa@mech.upatras.gr and pasialisv@gmail.com.

such as mass loss and material embrittlement of steel (Ref 2-4), along with micro- and macrocracking of concrete, result in a much more problematic structure than previously thought.

The underestimation of the problem arises from the fact that under normal conditions, concrete provides protection to the embedded steel. Furthermore, corrosion is usually not visible. Physical protection of the reinforcing steel against corrosion is provided by the dense and relatively impermeable concrete cover. Chemical protection is provided by the high alkalinity of the pore solution. Calcium, as well as potassium and sodium to a smaller extent, contribute to the high alkalinity $(\mathrm{pH}=13.5)$ of the pore solution. At this high $\mathrm{pH}$, steel is passivated due to the formation of a sub-microscopically thin $\gamma-\mathrm{Fe}_{2} \mathrm{O}_{3}$ film according to Ref 5, 6. This protective film protects the reinforcing steel from the access of aggressive ions and acts as an alkaline buffer to $\mathrm{pH}$ reductions resulting from the hydrolysis of corrosion products (Ref 7).

For corrosion to commence, the protective film on the steel-concrete interface must be broken or chemically dissolved (Ref 8). Proposed mechanisms by which chlorides break down the passive layer are the build up of metal holes at the film/ substrate interface (Ref 9) as well as local acidification and pitting caused by high chloride concentrations at the iron oxide/ pore solution interface. According to Leek and Poole (Ref 10), chloride ions initiate corrosion by breaking the bond between the passivating film and the metal. Tritthart (Ref 11) proposed that chloride ions-induced corrosion commences when a concentration threshold of free chloride ions in the vicinity of the bar is reached. The establishment of the threshold level is a matter of current interest.

Greece is a country with a long coastline and many major cities built on coastal areas. This causes extensive corrosion of the steel reinforcement of buildings due to the large chloride concentrations in the atmosphere. Furthermore, it is by far the most seismic country in Europe and the sixth most seismic country worldwide. Since 1960, when all constructions began utilizing reinforced concrete as the load-bearing structure, many earthquakes have occurred in Greece such as the major earthquake of Thessaloniki in 1978 (6.5 on the Richter scale), Aigio in 1995 (6.1 on the Richter scale), Athens in 1999 (5.9 on the Richter scale), Lefkada in 2003, (6.2 on the Richter 
scale), Kithira in 2006, (6.9 on the Richter scale) and many more, which led to numerous casualties caused by collapsed buildings.

Earthquakes cause stress events on the reinforcing steel in the region of low cycle fatigue (LCF). This was confirmed by Sheng and Gong (Ref 12). They investigated seismic ruins of Tangshan (China) and confirmed that the failure model of building structural steels under earthquake loading is LCF.

An effort to assess the effect of corrosion on the mechanical properties of reinforcing steel bars of Grade 60 of ASTM A615 (which is similar to BSt 420) was made by Almusallam. In his work (Ref 4), reinforcing steel bars of diameter $\varnothing 6$ and $\varnothing 8$ were embedded in concrete. The corrosion of the reinforcing steel bars was accelerated by partially immersing the specimens in a 5\% sodium chloride solution and impressing am anodic current of $2 \mathrm{~mA} / \mathrm{cm}^{2}$. After the desired level of corrosion was obtained, the steel bars were removed from the concrete matrix and tested in tension. A decrease in the maximum stress was observed and recorded, as well as a decrease in the elongation to failure of the steel bars with increasing corrosion. In the same work, discrimination between the actual (effective) and the nominal (apparent) stress was made.

In a previous study completed by Apostolopoulos et al. (Ref 13), the effects of gradually accumulating corrosion damage due to laboratory salt spray corrosion on the mechanical behavior of reinforcing steel bars grade BSt500s $\varnothing 8$ has been assessed. The results of this experimental investigation had shown that the corrosion exposure causes an appreciable mass loss which increases with increasing duration of exposure. This leads to a significant increase of the applied stress. In addition, a moderate reduction of the material's tensile strength values and a significant reduction of the tensile ductility were observed. For laboratory salt spray exposure times, which are realistic for simulating natural corrosion, the tensile properties of the steel bars drop to values lying below the limits set in the standards presently in force for using steels in reinforced concrete members.

The mechanical properties of reinforcing steel are most important in the case of RC structures, which are located in seismic areas. During the seismic erection, the reinforcement is often subjected to stress events at the region of LCF, in the form of high strain reversals. Thus, the need for a sufficient energy storage capacity of the material is imperative.

In the work performed by Apostolopoulos (Ref 14), the effects of gradually accumulating corrosion on the LCF behavior of S500s grade steel were assessed. This work had shown that corrosion causes an appreciable reduction in the ductility, strength, and the number of cycles to failure of the material.

In a previous work (Ref 15), the mechanical behavior of precorroded reinforcing steel bars S400 with respect to duration of laboratory salt spray corrosion was assessed. Both tensile and LCF test assessments were included, indicating a modest reduction of material's strength and a dramatic degradation of ductility properties as well as fatigue strength versus duration of corrosion. Structures utilizing S400 grade steel are 15 to 45 years old by now. In the case of coastal seismic countries such as Greece and Turkey, damage has accumulated on the loadbearing elements by corrosion as well as fatigue. No other works have been found in the available literature to account for the effects of corrosion on LCF behavior of S400 grade steel.

In incomplete structures as much as in structures with expansion provisions, the existing steel suspensions experience long-term damage accumulation, due to atmospheric corrosion (Fig. 1a). Although grade steel S400 (widely known as StIII or BSt420) has officially been withdrawn since the late 1990s from production, it still holds as the backbone of reinforced structures aging from 15 to 45 years.

Moreover, these old structures have accumulated damage due to seismic activity. Figure 1(b) displays the typical RC frame of the structure shown in Fig. 1(a) upon expansion completion. In a simplified approach, the horizontal plate movement which occurs during an earthquake generates bending moments (Fig. 1c) which in turn produces alternate normal forces on the reinforcement (Fig. 1d). It comes naturally that the reinforcement positions mostly affected (by both bending moments and corrosion), lay at the base of steel bar emersions. Therefore, fatigue strength of corroded steel reinforcement is considered to be a matter of serious academic interest.

The demand for an increased bonding between concrete and reinforcement has given rise to the establishment of ribbed steel in building constructions. Therefore, nowadays steel reinforcement is produced in the form of ribbed rebars. However, despite the fact that ribs increase the bond between steel and concrete, they have a detrimental effect on the fatigue strength of ribbed steel products. Ribs are considered to be stress concentration areas where crevices are more likely to occur during a dynamic loading and lead to early material failure.

Therefore, the case of existing smooth corroded S400 in terms of fatigue strength values compared to ribbed S400 has to be investigated.

The present study is sequential to the aforementioned work (Ref 15) and aims at exposing the negative effects of corrosion and ribs on fatigue behavior of reinforcing steel bars grade S400 $\varnothing 10$. Furthermore, research goes further by assessing fatigue behavior of ribbed and smooth grade steel S400 of nominal diameter $\varnothing 10$ under various LCF loadings with respect to mass loss due to laboratory-induced corrosion. Reinforcing steel suffering a mass loss equivalent to 90 days of accelerated corrosion has been found in structures aging from 15 to 45 years, depending on several factors such as the thickness and the quality of the concrete cover, their location relative to the sea, etc. Therefore, a 90-day exposure to the above corrosive environment will invoke a specific mass loss to steel bars which is realistic simulation of the natural corrosion damage which might accumulate during the service time of reinforced concrete structures. Consequently, all properties will appear as dependants of mass loss.

Ribbed and smooth specimens were subjected to single axis, sinusoidal loads of $0.5 \mathrm{~Hz}$ frequency and constant strain amplitudes of $\pm 1, \pm 2.5$, and $\pm 4 \%$ after being exposed to salt spray environment for different durations.

The experimental results of all tests performed will be presented along with those of the previous work (Ref 15) for comparison reasons.

\section{Experimental Procedure}

The experiments were conducted on S400 steel grade reinforcing steel, specially produced for the needs of the current investigation by a Greek steel mill. The material was delivered in the form of $10 \mathrm{~mm}$ nominal diameter ribbed bars. The exact chemical composition of the alloy is given in Table 1 . 


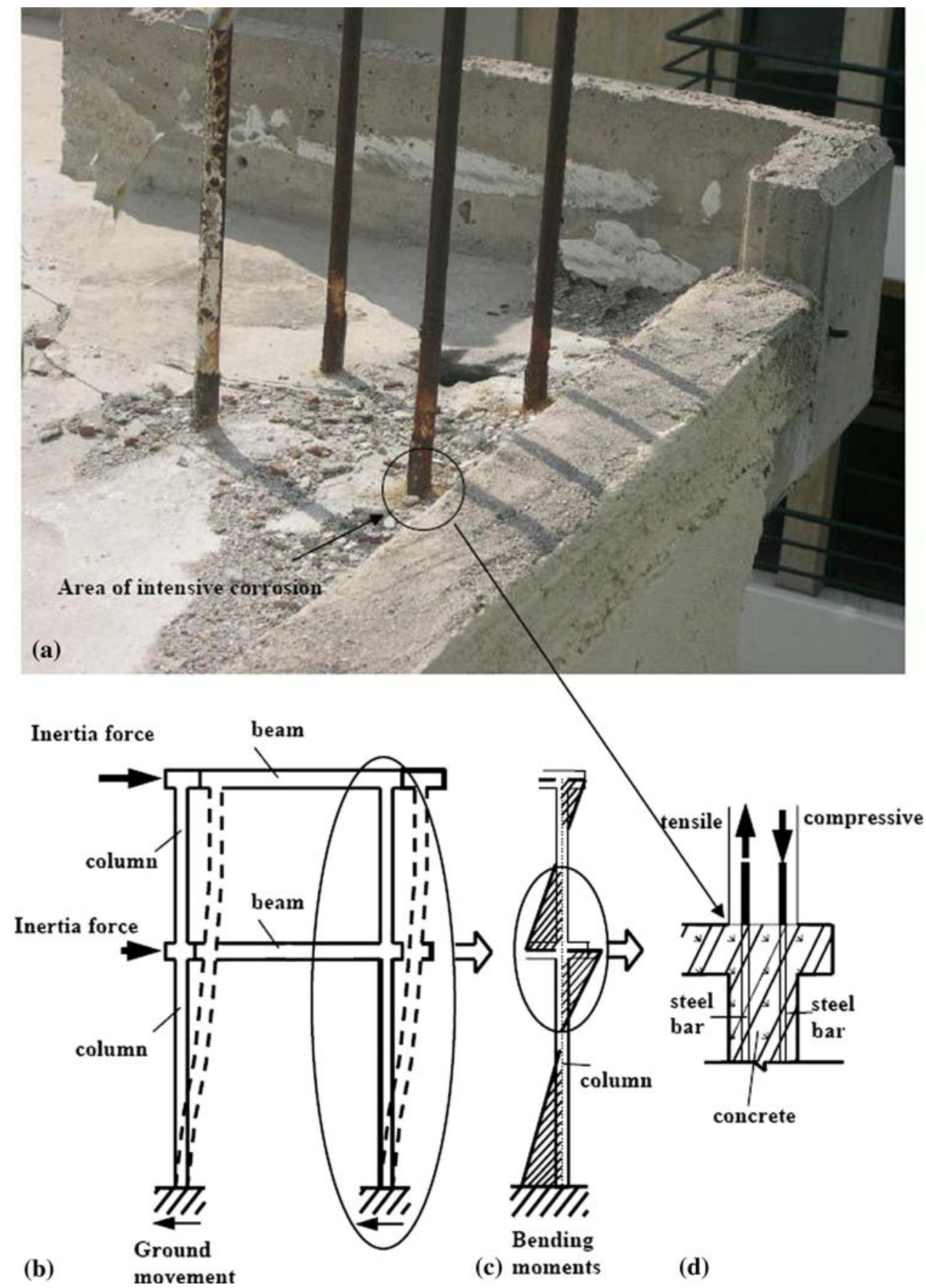

Fig. 1 (a) Steel reinforcements remain totally exposed to atmospheric corrosion in a building sited next to the sea. (b) Implication of inertial forces on a typical RC frame due to seismic erections. (c) Formation of internal bending moments. (d) Production of alternate normal forces on the reinforcement

Table 1 Chemical composition of the material under investigation

\begin{tabular}{cccccccccccc}
\hline $\mathbf{C} \%$ & Mn \% & S \% & P \% & Si \% & Ni \% & Cr \% & Cu \% & V \% & Mo \% & N \% \\
\hline 0.35 & 0.94 & 0.026 & 0.013 & 0.26 & 0.10 & 0.16 & 0.42 & 0.002 & 0.023 & 0.010 \\
\hline
\end{tabular}

Specimens of $170 \mathrm{~mm}$ in total length and $60 \mathrm{~mm}$ in gauge length were cut for the LCF tests. A gauge length equal to six times the nominal diameter was selected since it represents the typical distance between stirrups used in presently day construction required for resistance to seismic loads. Prior to the tests, the specimens were pre-corroded using accelerated laboratory corrosion tests in salt spray environment. LCF tests performed are summarized in Table 2. In total, 126 LCF tests 


\begin{tabular}{|c|c|c|c|c|c|}
\hline \multirow[b]{2}{*}{ Test series } & \multirow[b]{2}{*}{ Test series description } & \multirow{2}{*}{$\begin{array}{l}\text { Duration of accelerated } \\
\text { salt spray corrosion exposure }\end{array}$} & \multicolumn{3}{|c|}{ Number of LCF tests conducted } \\
\hline & & & $\varepsilon= \pm 1 \%$ & $\varepsilon= \pm \mathbf{2 . 5 \%}$ & $\varepsilon= \pm \mathbf{4 \%}$ \\
\hline 1 & LCF non-corroded & None (Reference) & 3 & 3 & 3 \\
\hline 2 & LCF corroded & 10 days & 3 & 3 & 3 \\
\hline 3 & LCF corroded & 20 days & 3 & 3 & 3 \\
\hline 4 & LCF corroded & 30 days & 3 & 3 & 3 \\
\hline 5 & LCF corroded & 45 days & 3 & 3 & 3 \\
\hline 6 & LCF corroded & 60 days & 3 & 3 & 3 \\
\hline 7 & LCF corroded & 90 days & 3 & 3 & 3 \\
\hline 8 & LCF non-corroded smooth & None (Reference) & 3 & 3 & 3 \\
\hline 9 & LCF corroded smooth & 10 days & 3 & 3 & 3 \\
\hline 10 & LCF corroded smooth & 20 days & 3 & 3 & 3 \\
\hline 11 & LCF corroded smooth & 30 days & 3 & 3 & 3 \\
\hline 12 & LCF corroded smooth & 45 days & 3 & 3 & 3 \\
\hline 13 & LCF corroded smooth & 60 days & 3 & 3 & 3 \\
\hline 14 & LCF corroded smooth & 90 days & 3 & 3 & 3 \\
\hline
\end{tabular}
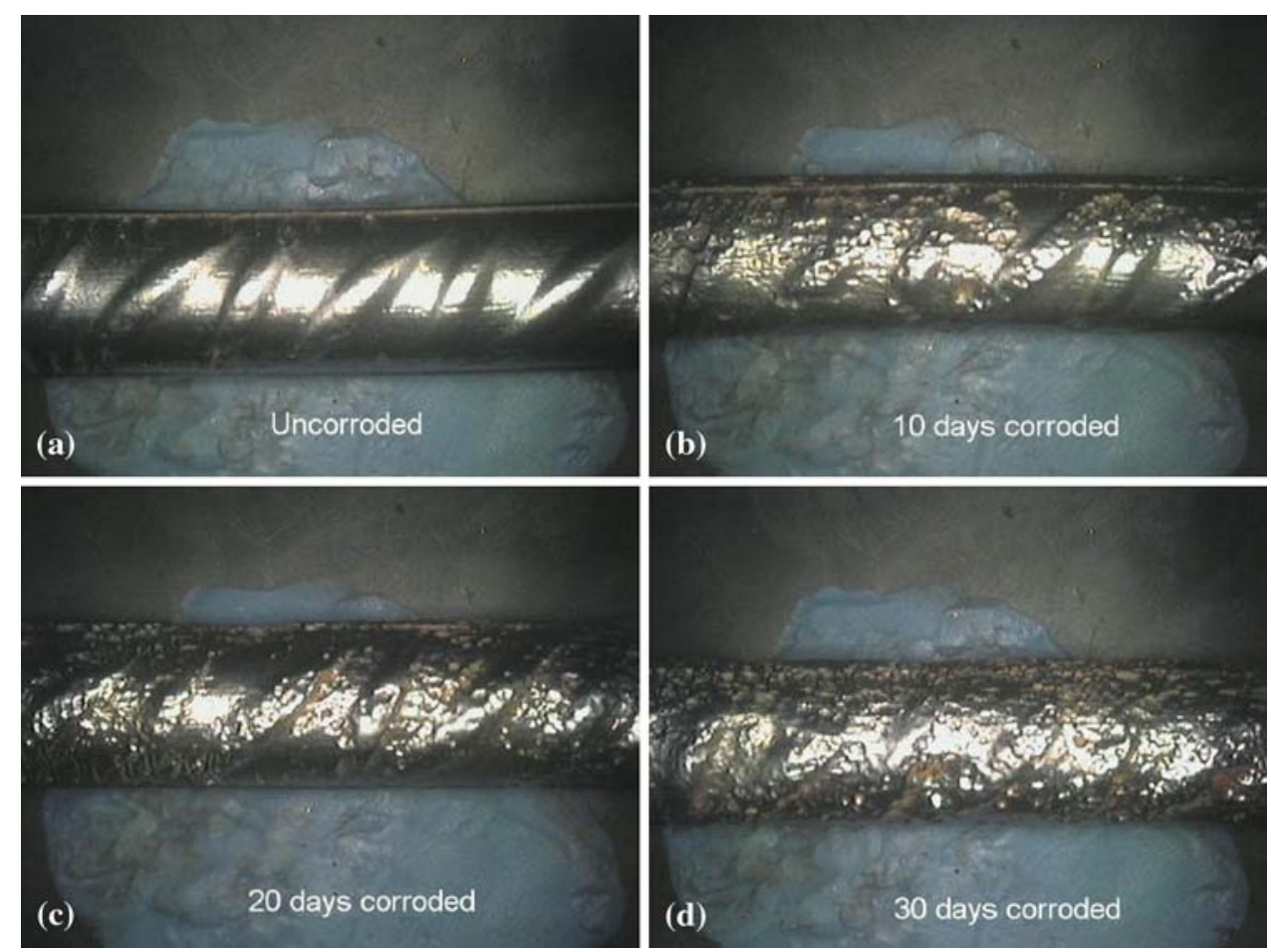

Fig. 2 Pitting corrosion on metal due to exposure to salt spray (fog) environment

were carried out along with 108 salt spray (fog) tests. Numbers in bold represent original experimentation in this work.

\subsection{Salt Spray Testing}

Salt spray (fog) tests were conducted according to the ASTM B117-94 specification. For the tests, a special apparatus, model SF 450 specially designed by Cand W. Specialist Equipment Ltd. was used. The salt solution was prepared by dissolving 5 parts by mass of sodium chloride $(\mathrm{NaCl})$ into 95 parts of distilled water. The $\mathrm{pH}$ of the salt spray solution was such that when dissolved at $35^{\circ} \mathrm{C}$, the solution was in the $\mathrm{pH}$ range from 6.5 to 7.2 at $25^{\circ} \mathrm{C}$. The temperature inside the salt spray chamber was maintained at $35+1.1-1.7^{\circ} \mathrm{C}$. The duration times of exposure were 10, 20, 30, 45, and 90 days. Upon completion, the specimens were washed with clean running water to remove the remaining salt deposits from their surfaces and then were dried. The oxide layer was removed using a bristle brush, according to the ASTM G1-90 specification (Ref 16). Figure 2 displays the decay of specimen's surface from the early stages of corrosion. It is obvious that pitting corrosion increases with duration of exposure.

The corrosion measured for the above-mentioned case appeared rather frequently during an extensive investigation on the integrity of older constructions at coastal sites in Greece. Even though the above results are not sufficient for establishing exact correlations between laboratory salt spray tests and natural corrosion, they clearly indicate that laboratory salt spray 
exposures for 90 days and over are realistic for simulating the natural corrosion damage of steel bars which might accumulate during the service time of reinforced concrete structures at coastal sites. Reinforcing steel suffering a mass loss equivalent to 90 days of accelerated corrosion has been found in structures aging from 15 to 45 years, depending on factors such as the thickness and the quality of the concrete cover, their location relative to the sea, etc. However, cases of even more severe mass loss of reinforcement have been recorded such as the case shown in Fig. 3 (building of social interest), where the recorded

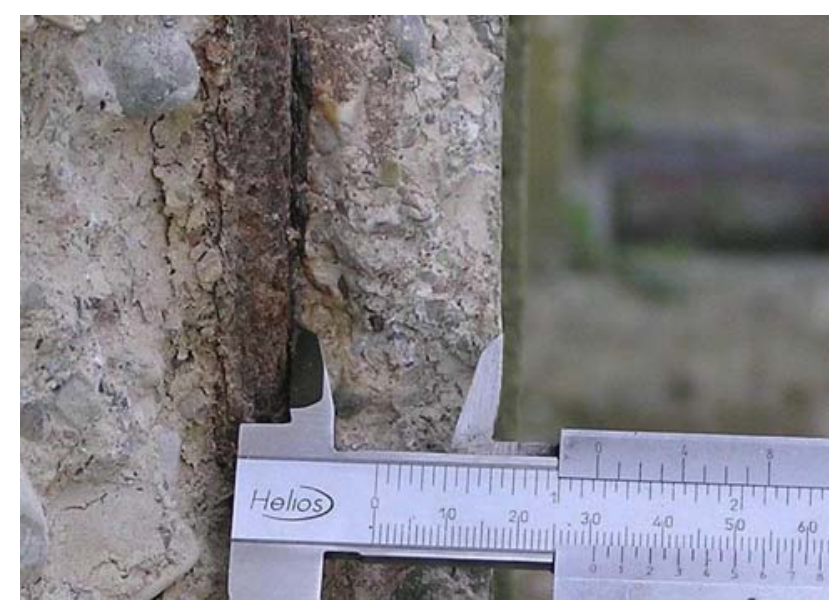

Fig. 3 Photograph showing a part of a structure where the corroded reinforcement increased its own volume forcing the removal of the concrete cover mass loss of a 25-year-old structure was locally up to $36 \%$ despite the fact that the minimum protective concrete cover was thick enough (as instructed by the Hellenic regulations).

\subsection{Final Preparations for LCF Tests}

Before testing, specimens intended for LCF tests are divided in two groups. The first group is intended directly for LCF tests. The second, is undergone a special treatment in which ribs are totally removed by means of filing from the central gauge area of the specimens. All specimens are weighed and marked prior to LCF tests.

\subsection{LCF Tests}

For the LCF tests, specimens of $60 \mathrm{~mm}$ gauge length $(6 \times$ nominal diameter $)$ were used. The LCF tests were performed on the same servo-hydraulic MTS $250 \mathrm{kN}$ machine used for the tensile tests. Holding of specimens between grips can be seen in Fig. 4. The tests were strain controlled, and the total strain levels selected were $\pm 1, \pm 2.5$, and $\pm 4 \%$. The sinusoidal cycling frequency was $0.5 \mathrm{~Hz}$, as seen in Fig. 5, which is in the frequency range recorded for a number of earthquakes (Ref 12). Material's density is assumed to remain unaffected by corrosion, constant with time, and equal to $\rho=78.5 \mathrm{gr} / \mathrm{cm}^{3}$.

The number of cycles to failure, the dissipated energy and the maximum tensile, and compressive force per fatigue cycle of the steel bars were evaluated. The total dissipated energy was evaluated by means of numerical integration of the loop areas of force-displacement diagrams, shown in Fig. 6. Note that LCF tests must always initialize to the tensile region; otherwise,
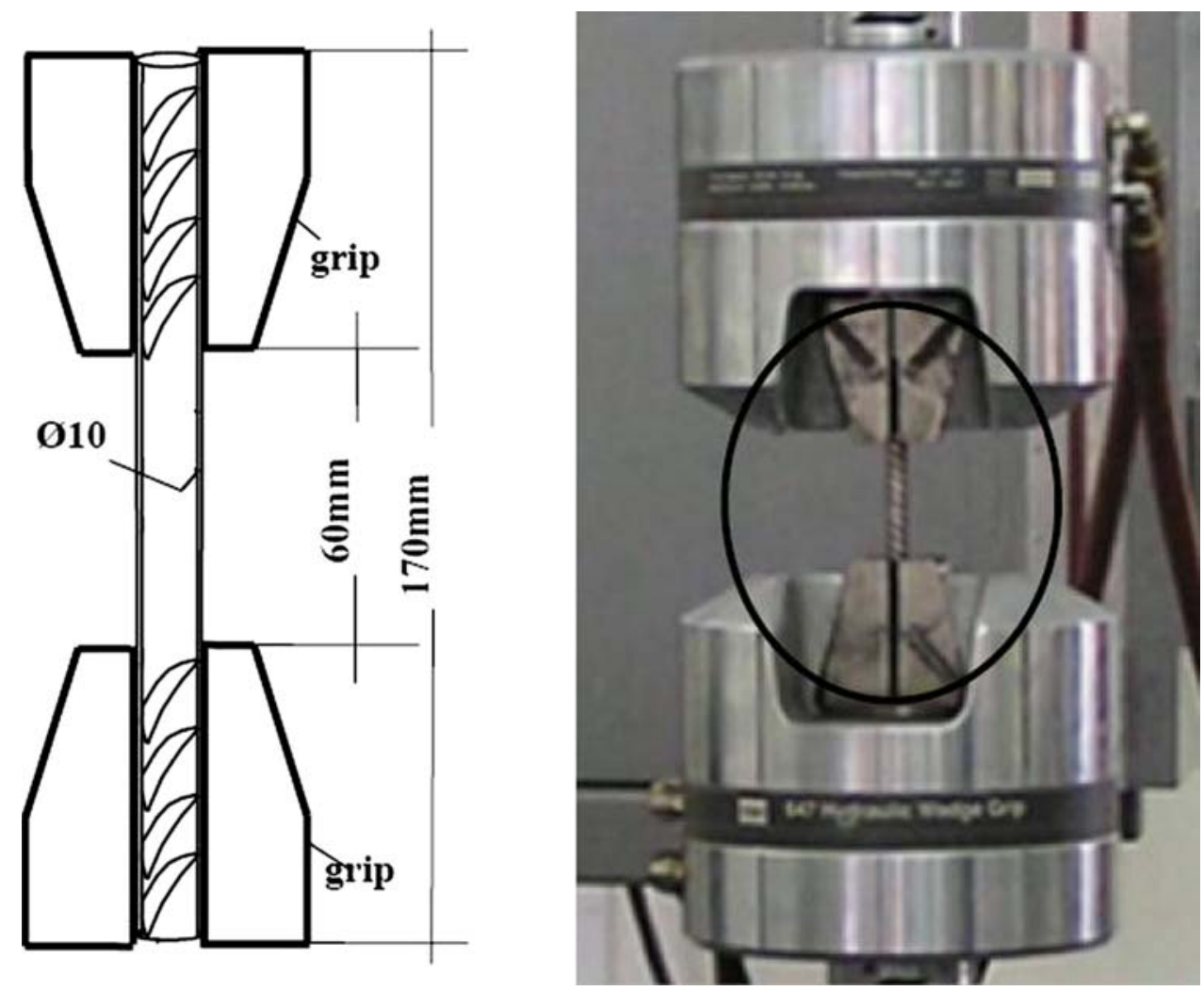

Fig. 4 Schematic showing the way (here smooth) specimens were held between grips for LCF tests and photograph of a LCF test 


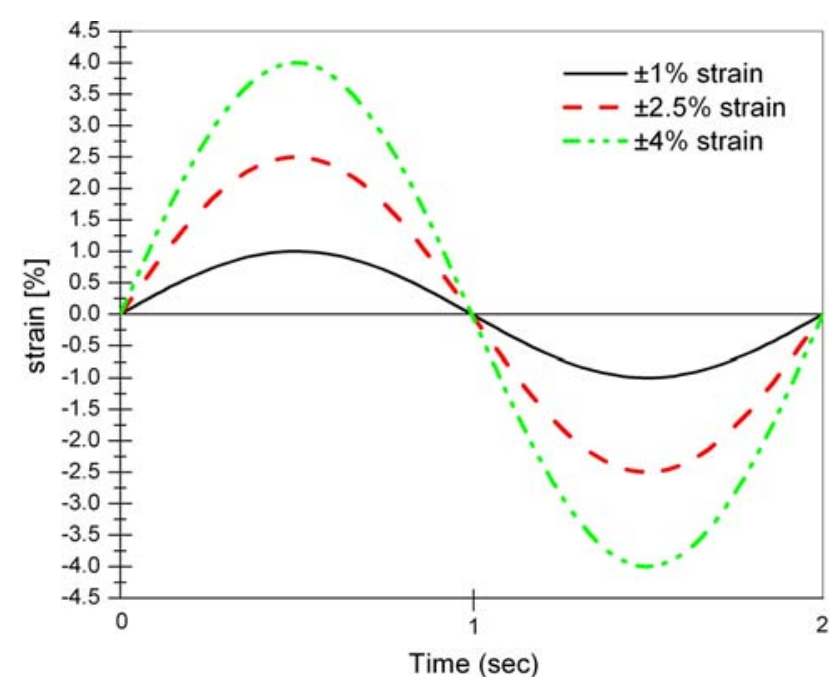

Fig. 5 The testing machine received as input these three strain waveforms

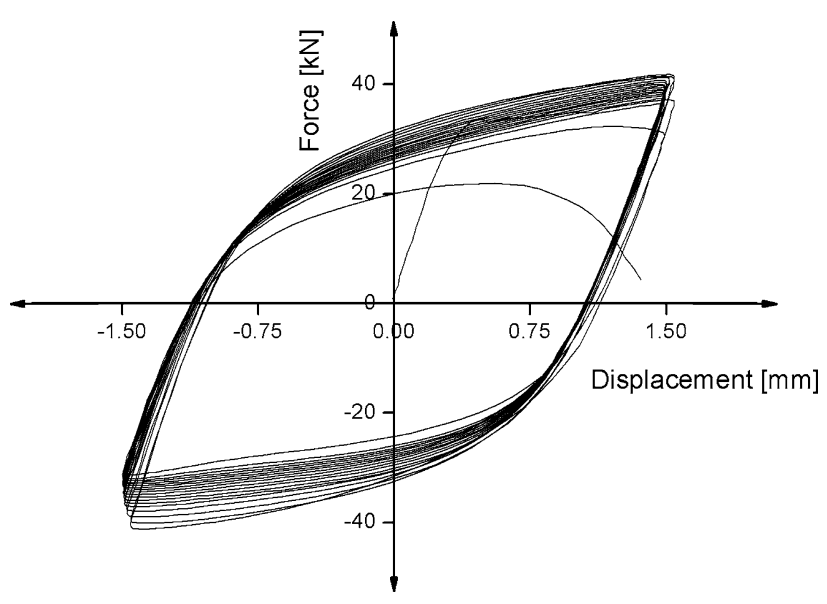

Fig. 6 Indicative LCF Force-displacement curves of a specimen tested to fracture with $\pm 2.5 \%$ strain

slightly different results may be obtained due to fatiguestrengthening effect of compression (Ref 17).

\section{Results and Discussion}

As expected, corrosion damage increases with increasing duration of exposure time to salt spray environment. The exposure causes the production of an oxide layer which covers the specimen and increases its thickness versus exposure time. The production of the oxide layer is associated to an appreciable loss of the specimen's mass. As can be seen in Table 3, accelerated salt spray corrosion for 90 days causes a mass loss of approximately $8.48 \%$. Although there is no direct correlation between natural and accelerated salt spray corrosion, the results clearly indicate that accelerated corrosion times of 90 days or more are realistic, if one compares the mass loss observed during the laboratory tests and that observed on the reinforcement of existing buildings (Ref 15) such as the case shown in Fig. 3.
Table 3 Values of reduced specimen mass (\%) and diameter $(\%)$

\begin{tabular}{llllllll}
\hline & \multicolumn{6}{c}{$\begin{array}{c}\text { Exposure to salt spray } \\
\text { corrosion environment, days }\end{array}$} \\
\cline { 2 - 9 } Property & $\mathbf{0}$ & $\mathbf{1 0}$ & $\mathbf{2 0}$ & $\mathbf{3 0}$ & $\mathbf{4 5}$ & $\mathbf{6 0}$ & $\mathbf{9 0}$ \\
\hline Mass loss, \% & 0 & 1.58 & 2.5 & 3.77 & 5.18 & 7.23 & 8.48 \\
Diameter loss, \% & 0 & 0.8 & 1.3 & 1.9 & 2.6 & 3.7 & 4.3 \\
\hline
\end{tabular}

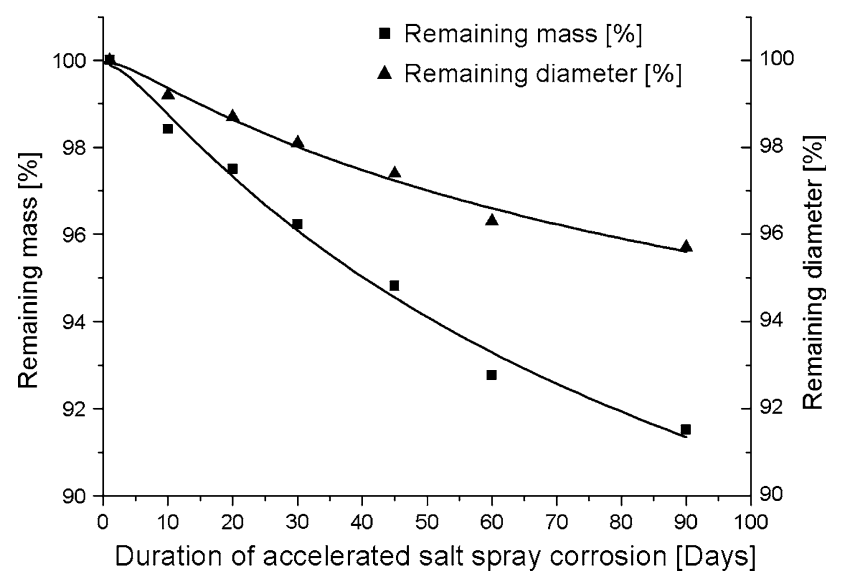

Fig. 7 Remaining mass (\%) and remaining diameter (\%) as a function of the duration of corrosion exposure

The dependency of the remaining mass on the duration of accelerated salt spray corrosion is shown in Table 3. The derived dependency may be fitted using the Weibull function

$f(t)=C_{1}+\frac{C_{2}-C_{1}}{\mathrm{e}^{\left(\log t / C_{3}\right)^{C_{4}}}}$

The constants $C_{1}, C_{2}, C_{3}$, and $C_{4}$ are calculated by least squares approximation. By assuming a uniform production of the oxide layer around the specimen and hence a uniform mass loss, the reduction of the nominal specimen diameter with increasing duration of the salt spray test can be calculated. Percent mass loss $\omega$ is defined as:

$\omega=\frac{m_{0}-m_{\mathrm{c}}}{m_{0}} \cdot 100 \%$

where $m_{0}$ is the mass of the uncorroded specimen and $m_{\mathrm{c}}$ is the reduced mass of the corroded specimen. Furthermore, assuming that the density of the material remains unaffected by corrosion leads to

$\frac{m_{\mathrm{c}}}{m_{0}}=\frac{d_{\mathrm{c}}^{2}}{d_{0}^{2}}$

By combining (2) and (3), the reduced diameter $d_{\mathrm{c}}$ is calculated as

$d_{\mathrm{c}}=d_{0} \sqrt{(1-\omega)}$

where $\omega$ is the measured mass loss fraction and $d_{0}$ is the nominal diameter of the uncorroded specimens $(10 \mathrm{~mm})$. The reduced values for the nominal specimen diameter are given in Table 3 and were fitted by the same Weibull function (1). The results for remaining mass and diameter versus corrosion 
level are displayed in Fig. 7 while Table 4 displays the calculated Weibull values $C_{1}-C_{4}$. The statistical coefficient of determination $R^{2}$ is a measure of the quality of regression. Ideal fitting is achieved for $R^{2}=1$.

The fatigue tests which were performed have shown that corrosion and the presence of ribs on the surface of the bars seriously affect the ability of the material to withstand strain

Table 4 Weibull constant values for remaining mass (\%) and diameter $(\%)$

\begin{tabular}{lccccc}
\hline & \multicolumn{5}{c}{ Weibull constant values } \\
\cline { 2 - 5 } Property & C1 & C2 & C3 & C4 & $\boldsymbol{R}^{\mathbf{2}}$ \\
\hline $\begin{array}{c}\text { Remaining } \\
\text { mass, \% }\end{array}$ & 69.32639 & 99.89621 & 2.76148 & 3.22034 & 0.98952 \\
$\begin{array}{c}\text { Remaining } \\
\text { diameter, \% }\end{array}$ & 8.44153 & 9.99448 & 2.74184 & 3.26958 & 0.98787 \\
\hline
\end{tabular}

cycling. Figure 8 displays qualitatively the effect of these two factors on the mechanical behavior of S400 $\varnothing 10$ under LCF.

As shown in (the indicative) Fig. 8, corrosion affects the maximum tensile and compression force per cycle as well as its expectancy life in terms of strain cycling. The presence of ribs on the surface of the specimens seems to have a bipolar effect on LCF behavior of steel reinforcement. The maximum tensile and compression force per cycle is slightly decreased in smooth specimens, whereas the number of cycles before fracture of the same specimens is appreciably increased.

A suitable measure which co-estimates strength and duration under LCF is the energy that steel bars can dissipate. An earthquake will inevitably transmit an amount of energy to a $\mathrm{RC}$ structure. As long as this energy is mostly dissipated by the reinforcement, the concrete is less loaded and thus the structure's integrity is ensured.

From the LCF tests, the total dissipated energy density was evaluated as the sum of the areas enclosed in the hysteresis
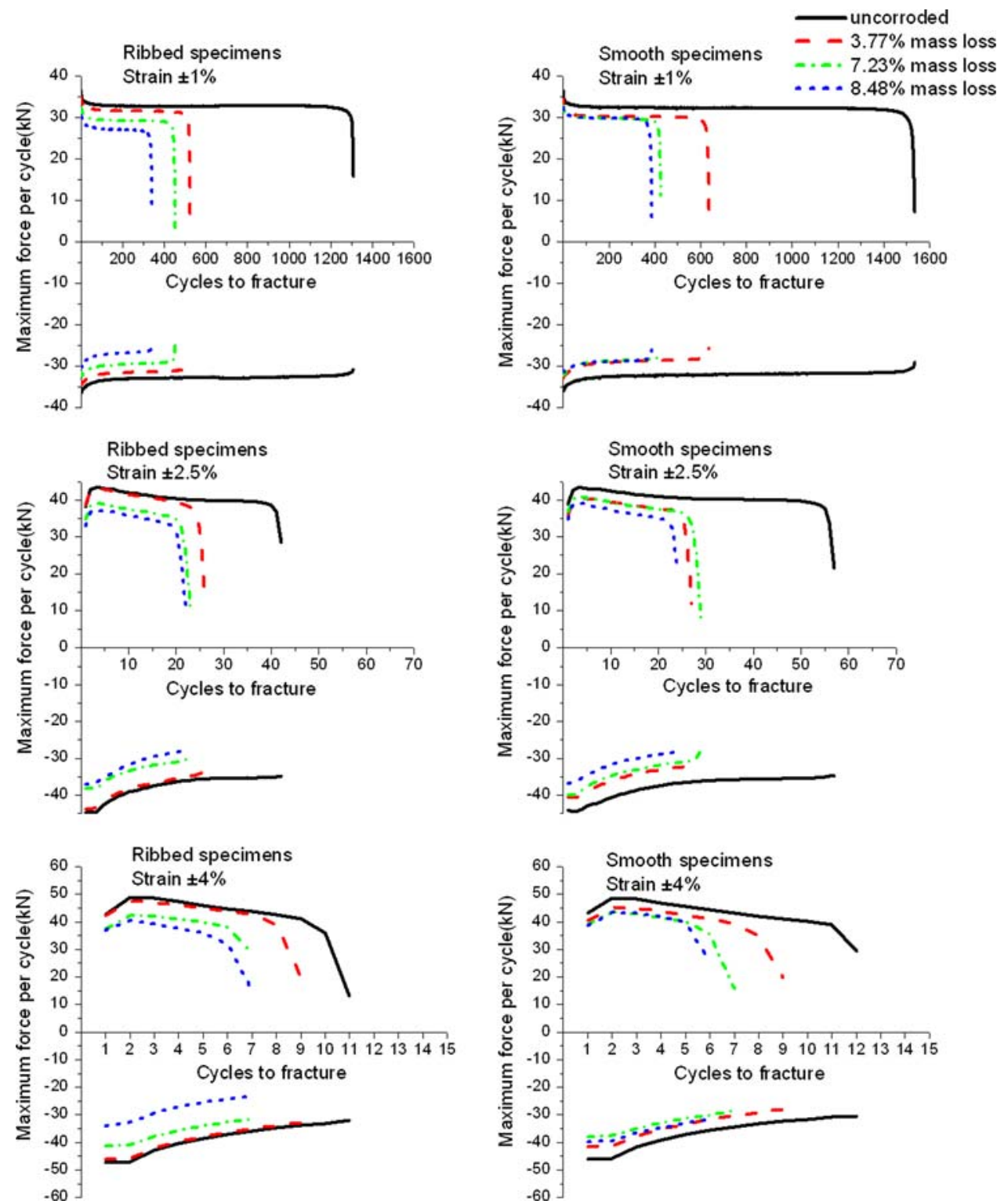

Fig. 8 Maximum tensile and compressive force per cycle, for strain $\pm 1, \pm 2.5$, and $\pm 4 \%$ 


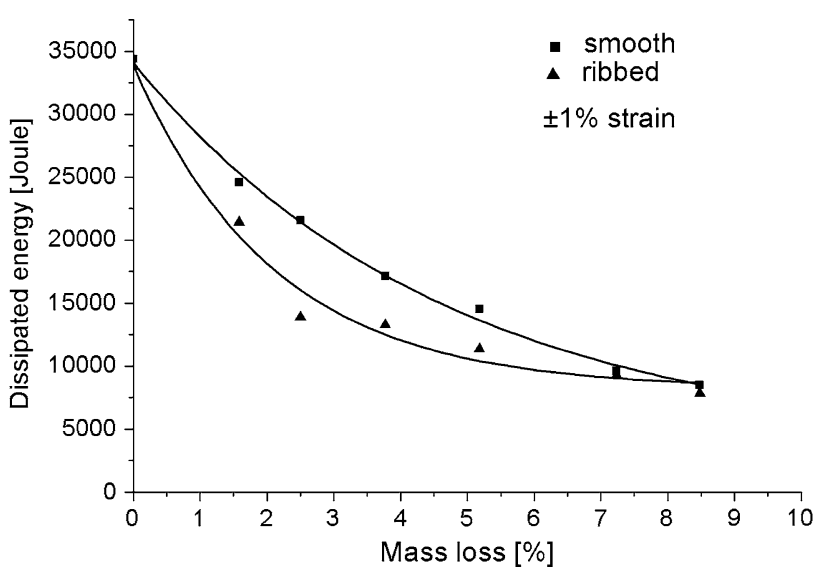

Fig. 9 Degradation of dissipated energy vs. mass loss for $\pm 1 \%$ strain

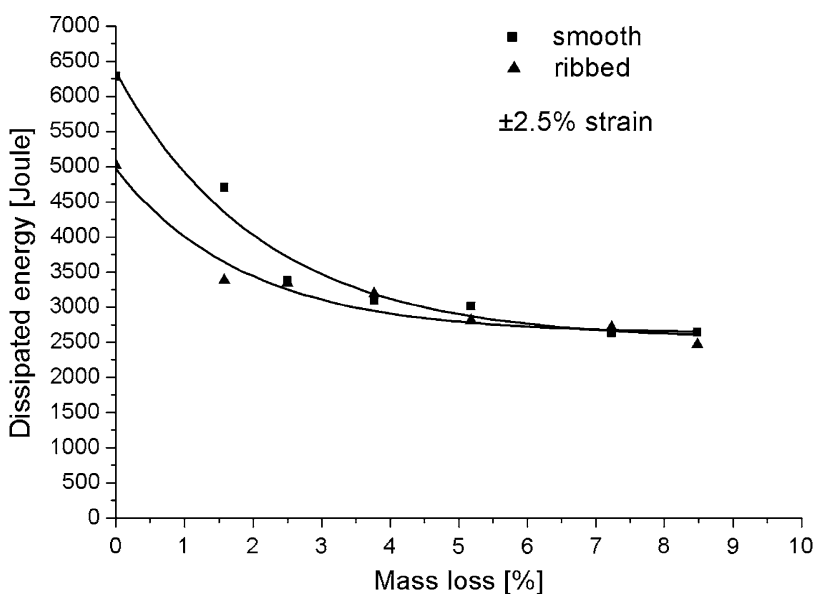

Fig. 10 Degradation of dissipated energy vs. mass loss for $\pm 2.5 \%$ strain

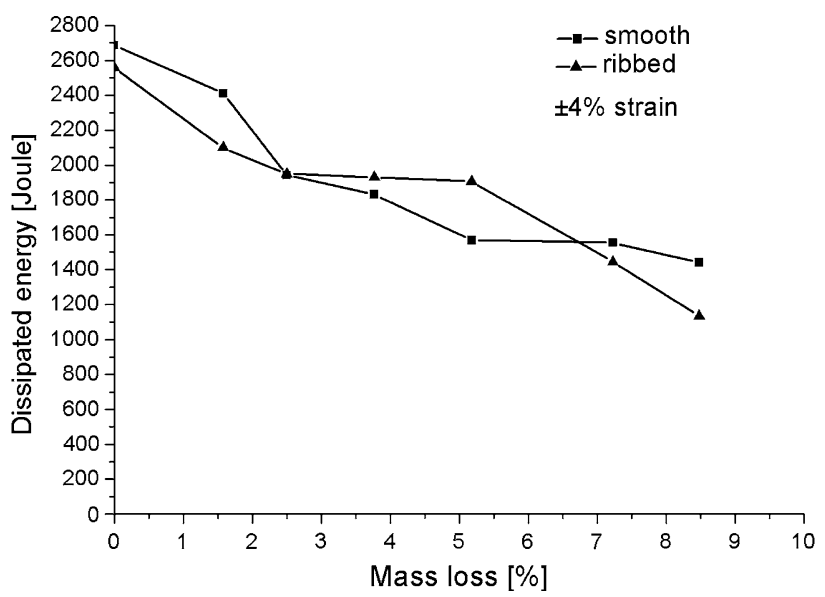

Fig. 11 Degradation of dissipated energy vs. mass loss for $\pm 4 \%$ strain

loops. Figures 9-11 show the reduction of the total dissipated energy of the smooth specimens with mass loss due to advancing corrosion, which are compared against the total

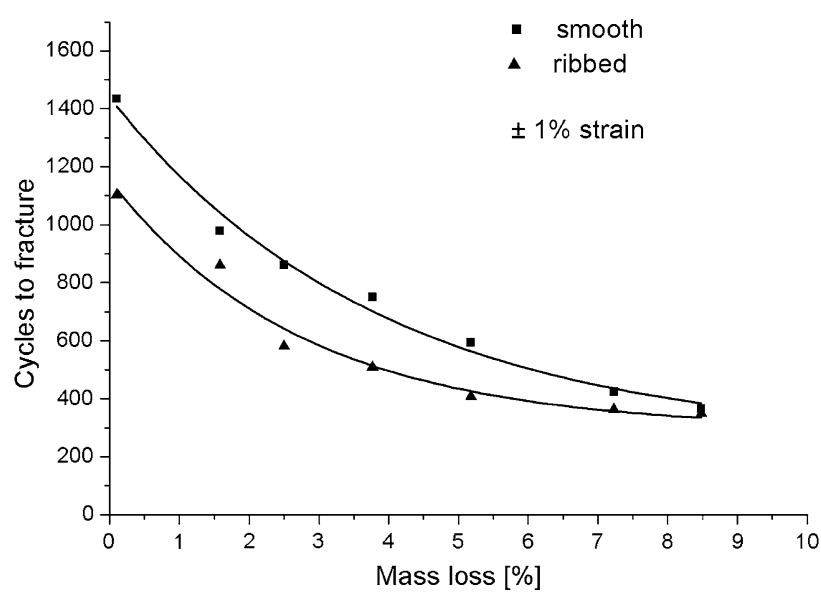

Fig. 12 Decrease in cycles to fracture vs. mass loss for $\pm 1 \%$ strain

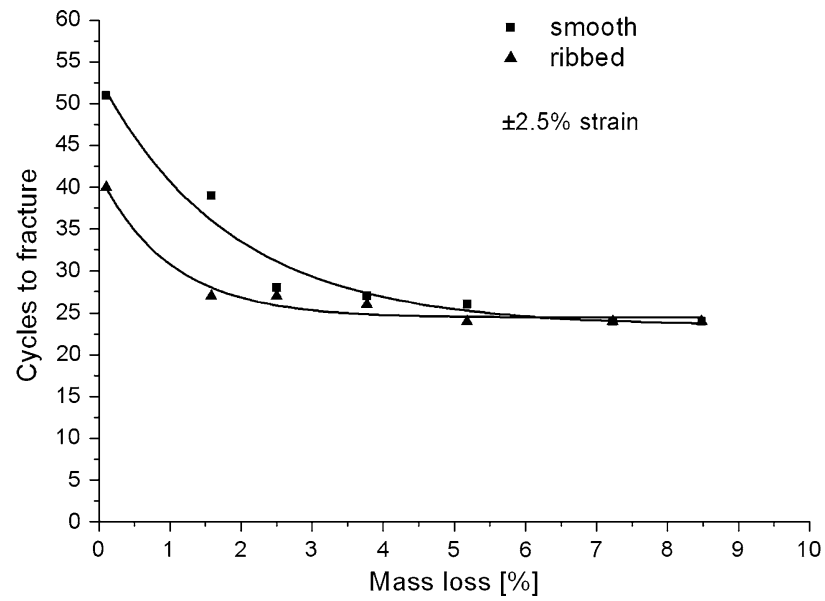

Fig. 13 Decrease in cycles to fracture vs. mass loss for $\pm 2.5 \%$ strain

dissipated energy of ribbed specimens. The derived dependency may be well fitted using the exponential function:

$y(m)=p_{1} \cdot e^{\left(-m / p_{2}\right)}+p_{3}$

It is obvious that smooth specimens have larger energy density to dissipate in LCF than ribbed specimens, despite the mass loss caused by the smoothing, which varies from about $2.5 \%$ for uncorroded specimens to $0.1 \%$, for maximum corroded specimens.

However, this energy dissipation capacity of smooth specimens declines exponentially with mass loss for \pm 1 and $\pm 2.5 \%$ strain and is completely eliminated after corrosion has caused a certain amount of weight decrease, as can be seen in both Fig. 9 and 10. Moreover, for strain amplitudes as high as $\pm 4 \%$, smooth specimens offer no advantage in terms of dissipated energy (Fig. 11).

Finally, the number of cycles before fracture with respect to mass loss was assessed, for the same strain amplitudes as before (Fig. 12-14). It is obvious that smooth specimens are able to withstand more cycles before fracture than ribbed specimens. This ability gradually decays with corrosion until it completely 


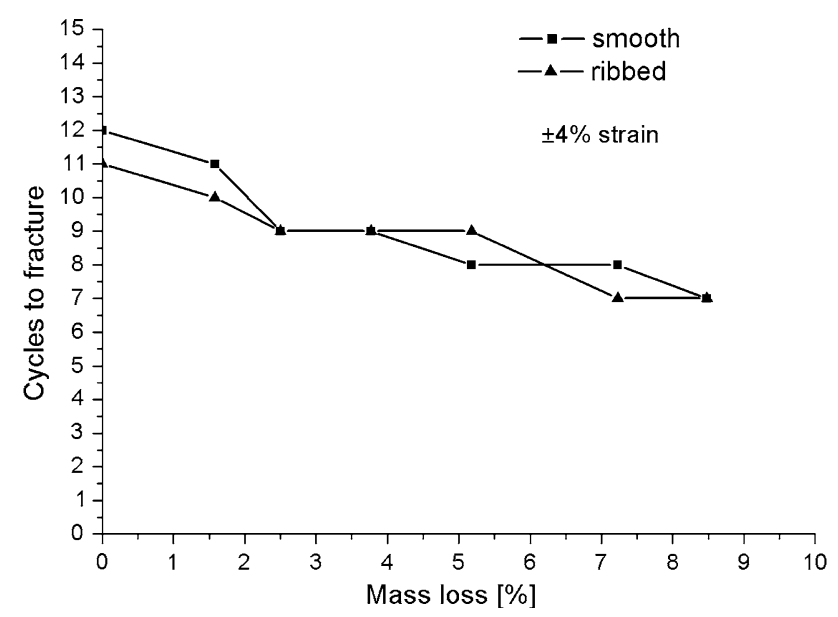

Fig. 14 Decrease in cycles to fracture vs. mass loss for $\pm 4 \%$ strain

Table 5 Exponential values for fitting cycles to fracture and dissipated energy

\begin{tabular}{lccccr}
\hline & \multicolumn{2}{c}{ Ribbed specimens } & & \multicolumn{2}{c}{ Smooth specimens } \\
\cline { 2 - 3 } Coefficients & $\begin{array}{c}\text { Cycles to } \\
\text { fracture }\end{array}$ & $\begin{array}{c}\text { Dissipated } \\
\text { energy, J }\end{array}$ & & $\begin{array}{c}\text { Cycles to } \\
\text { fracture }\end{array}$ & $\begin{array}{c}\text { Dissipated } \\
\text { energy, J }\end{array}$ \\
\hline Strain amplitude $\pm 1 \%$ & & & & \\
P1 & 294.08585 & 8208.1826 & & 249.79817 & 3571.57092 \\
P2 & 858.95908 & 25660.4524 & & 1188.88231 & 30526.03454 \\
P3 & 2.76427 & 2.10692 & & 3.893 & 4.66997 \\
$R^{2}$ & 0.97655 & 0.98778 & & 0.98952 & 0.99626 \\
Strain amplitude $\pm 2.5 \%$ & & & \\
P1 & 24.42284 & 2626.76662 & & 23.42963 & 2535.52951 \\
P2 & 17.08284 & 2333.4177 & & 29.59132 & 3806.09013 \\
P3 & 1.01228 & 1.89811 & & 1.85702 & 2.13515 \\
$R^{2}$ & 0.97795 & 0.95616 & & 0.96835 & 0.96263 \\
\hline
\end{tabular}

disappears. Again, for strain amplitudes as high as $\pm 4 \%$, smooth specimen offers no advantage in total cycles before fracture (Fig. 14), since stress concentration on ribs no longer seems to have any effect on material's mechanical behavior under LCF. The dependency of cycles with mass loss for \pm 1 and $\pm 2.5 \%$ strain may be well fitted using (5). The exponential values $\mathrm{P}_{1}-\mathrm{P}_{3}$ for Fig. 12 and 13 are given in Table 5. No mathematical curve was found to fit well the dependency of cycles and energy dissipation of both ribbed and smooth specimens with mass loss for $\pm 4 \%$ strain.

Comparisons between ribbed and smooth specimens are summarized in Table 6 where the percentage of the degradation of cycles to failure and dissipated energy caused by $3.77 \%$ mass loss for 30 days of corrosion and $8.48 \%$ mass loss for 90 days of corrosion, for strain amplitudes of $\pm 1, \pm 2.5$, and $\pm 4 \%$ are estimated. It appears that from the early stages of corrosion, fatigue strength of ribbed and smooth specimens is dramatically reduced. A relatively small mass loss of about $3.77 \%$ due to corrosion induces disproportional fatigue strength degradation, in terms of cycles to fracture and energy dissipation. This is explained since steel corrosion creates pits on the metal surface which are stress concentration regions. However, at high strain amplitudes as high as $\pm 4 \%$, stress
Table 6 Percentage of total decrease in cycles to failure and dissipated energy for 3.77 and $8.48 \%$ mass loss

\begin{tabular}{|c|c|c|c|c|}
\hline \multirow[b]{2}{*}{$\begin{array}{l}\text { Mass } \\
\text { loss, \% }\end{array}$} & \multicolumn{2}{|c|}{ Ribbed specimens } & \multicolumn{2}{|c|}{ Smooth specimens } \\
\hline & $\begin{array}{c}\text { Cycles to } \\
\text { fracture, \% }\end{array}$ & $\begin{array}{c}\text { Dissipated } \\
\text { energy, J, \% }\end{array}$ & $\begin{array}{c}\text { Cycles to } \\
\text { fracture, \% }\end{array}$ & $\begin{array}{c}\text { Dissipated } \\
\text { energy, J, \% }\end{array}$ \\
\hline \multicolumn{5}{|c|}{ Strain amplitude $\pm 1 \%$} \\
\hline 3.77 & 64 & 63 & 51 & 50 \\
\hline 8.48 & 72 & 76 & 76 & 78 \\
\hline \multicolumn{5}{|c|}{ Strain amplitude $\pm 2.5 \%$} \\
\hline 3.77 & 38 & 39 & 49 & 51 \\
\hline 8.48 & 40 & 49 & 51 & 57 \\
\hline \multicolumn{5}{|c|}{ Strain amplitude $\pm 4 \%$} \\
\hline 3.77 & 18 & 27 & 25 & 34 \\
\hline 8.48 & 36 & 51 & 42 & 46 \\
\hline
\end{tabular}

concentration (on ribs or on pits) seems to have no effect on material's mechanical behavior under LCF, and mass loss appears to be the primary factor for fatigue strength degradation of steel reinforcement.

Older structures in earthquake prone areas are not expected to display a constant load-bearing ability beyond a certain service life. The antiseismic design regulations currently in force do not account for the maximum and cumulative plastic strain demands and the strain history that a structure will suffer under corrosive environment and severe ground motion that could lead to unpredictable performance.

\section{Conclusions}

The exposure of the steel bars S400, the Hellenic equivalent to BSt 420, to salt spray environment results in an appreciable mass loss which increases with increasing duration of exposure. Although, currently there is no direct correlation between the accelerated laboratory salt spray test and the natural corrosion of reinforcing steels such as to assess a realistic duration for the accelerated laboratory salt spray test, reinforcing steel suffering a mass loss equivalent to 90 days of accelerated corrosion has been found in structures aging from 15 to 45 years.

Comparisons between the mechanical behavior of ribbed and smooth S400 steel bars under LCF are made. It is clearly seen that despite the fact that smoothing slightly decreases the maximum tensile and compression force per cycle, an appreciable increase in the useful life of the material is recorded. This is more evident at relatively low strain amplitudes, whereas the effect diminishes with increasing strain amplitude.

The use of locally smooth reinforcing steel bars could be considered in the proximity of column bases, since in that area the bending moments caused by seismic erections is maximized.

Present day standards for calculating strength of reinforced concrete members do not account for the appreciable property degradation of the reinforcing steel bars due to the gradually accumulating corrosion damage. A revision of the standards such as to account for the above corrosion effects on the material properties seems to be required, since nowadays, many restoration works and further building expansions are planned and performed on aged RC structures utilizing S400 grade steel, without considering the effects of corrosion. 
Furthermore, no standards have been imposed for the execution of LCF tests, as they do for high-cycle fatigue tests, and those currently in use do not specify a minimum LCF resistance of steel reinforcing bars at each level of earthquake loading and structural ductility.

Therefore, LCF along with corrosion on steel reinforcing bars set a combined problem which is still open to scientific research.

\section{References}

1. K. Vandoros and S. Dritsos, Concrete Jacket Construction Detail Effective When Strengthening RC Columns, Constr. Build. Mater. 2008, 22(3), p 264-276

2. C. Fang, K. Lundgren, L. Chen, and C. Zhu, Corrosion Influence on Bond in Reinforced Concrete, Cement Concr. Res., 2004, 34, p 2159 2167

3. G. Batis and E. Rakanta, Corrosion of Steel Reinforcement Due to Atmospheric Pollution, Cement Concr. Compos., 2005, 27, p 269-275

4. A.A. Almusallam, Effect of Degree of Corrosion on the Properties of Reinforcing Steel Bars, Constr. Build. Mater, 2001, 15(8), p 361-368

5. M. Pourbaix, Applications of Electrochemistry in Corrosion Science and Practice, Corros. Sci., 1974, 14, p 25-28

6. M. Pourbaix, Atlas of Electrochemical Equilibria in Aqueous Solutions (translated by J.A. Franclin, Ed.), Pergamon Press, New York, 1966, p 312

7. C.L. Page and K.W.J. Treadaway, Aspects of Electrochemistry of Steel in Concrete, Nature, 1982, 279(5862), p 109-115
8. T.P. Hoar, The Anodic Behavior of Metals, Corros. Sci., 1967, 7, p 341-355

9. C.Y. Chao, L.F. Lin, and D.D. MacDonald, A Point Defect Model for Anodic Passive Films, Part I: Film Growth Kinetics Part II: Chemical Breakdown and Pit Initiation, J. Electrochem. Soc., 1981, 128, p 11871194

10. D.S. Leek and A.B. Poole, The Breakdown of the Passive Film on High Yield Mild Steel by Chloride Ions, in Corrosion of Reinforcement in Concrete, C.L. Page, R.W. Treadawy, and P.B. Bamforth, Ed., Elsevier Science, London, 1990, p 65-73

11. Tritthart J, Pore Solution Composition and Other Factors Influencing the Corrosion Risk of Reinforcement in Concrete, in Corrosion of Reinforcement in Concrete, C.L. Page, R.W. Treadawy, and P.B. Bamforth, Ed., Wishaw, Warwickshire, UK, May 21-24, 1990, p 96-106

12. G.M. Sheng and S.H. Gong, Investigation of Low Cycle Fatigue Behavior of Building Structural Steels Under Earthquake Loading, Acta Metallur. Sin. (Engl. Lett.), 1997, 10(1), p 51-55

13. C.A. Apostolopoulos, M.P. Papadopoulos, and S.G. Pantelakis, Tensile Behavior of Corroded Reinforcing Steel Bars BSt500s, Constr. Build. Mater., 2006, 20, p 782-789

14. C.A. Apostolopoulos, Mechanical Behavior of Corroded Reinforcing Steel Bars S500s Tempcore Under Low Cycle Fatigue, Constr. Build. Mater., 2007, 21(7), p 1447-1456

15. C.A. Apostolopoulos and M.P. Papadopoulos, Tensile and Low Cycle Fatigue Behavior of Corroded Reinforcing Steel Bars S400, Constr. Build. Mater, 2007, 21(4), p 855-864

16. ASTM G1-90 (1999) e1 Standard Practice for Preparing, Cleaning, and Evaluating Corrosion Test Specimens, ASTM International, January 1, 1999, 8 pp

17. J.E. Shigley and C.R. Mischke, Mechanical Engineering Design, 6th ed., Mc Graw Hill, New York, 2001, p 361 